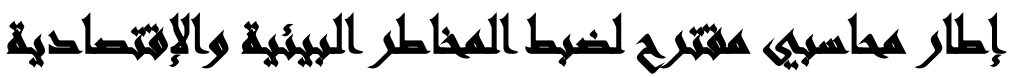

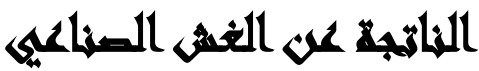

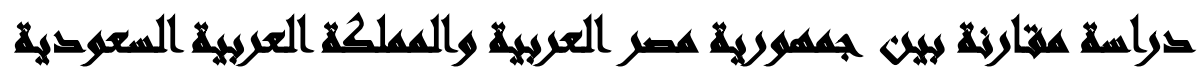

[17]

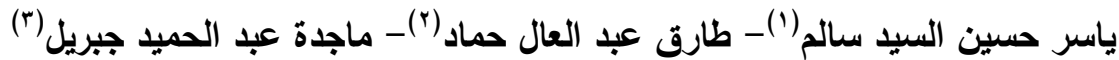

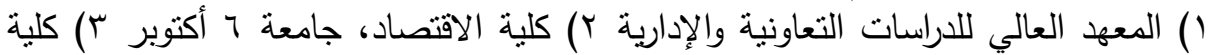

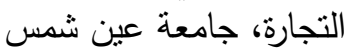

\section{المستخلم}

تنتاول الدراسة مواجهة ظاهرة الغش الصناعي وذلك للحد من تكلفة المخاطر البيئية

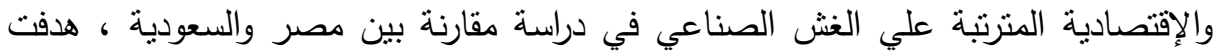

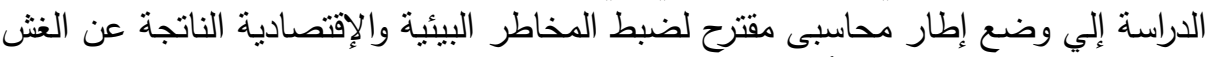
الصناعي ، وفي سبيل ذللك أستهدفت الدراسة دراسة وتحليل ظاهرة الغش الصناعي وتوضيح

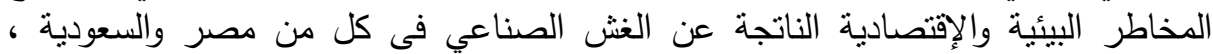

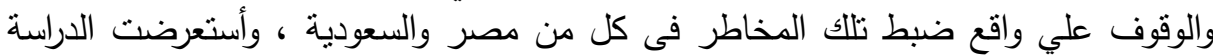
دور المحاسبة البيئية فى حل المشكلات الناتجة عن العملية الصناعية وقد تم استخدام المنهج

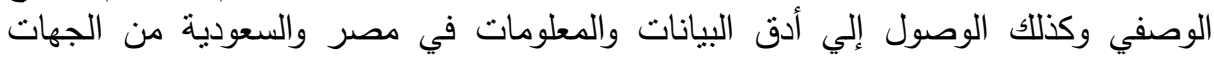

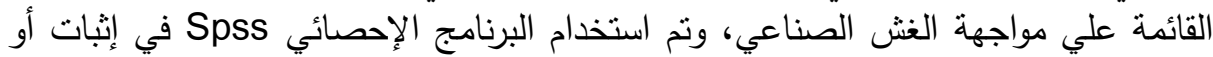

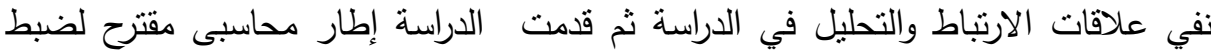

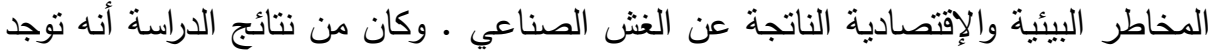

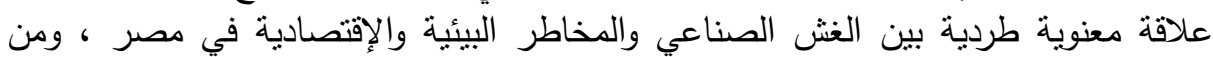

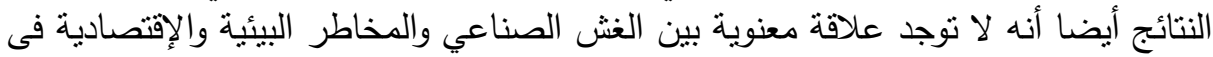

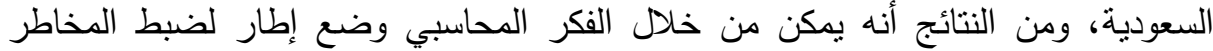
البيئية والاقتصادية الناتجة عن الغش النه الصناعي.

ومن توصيات الدراسة ضرورة الإهتمام بتطوير كافة منظمات التهات حماية البيئة وتوفير

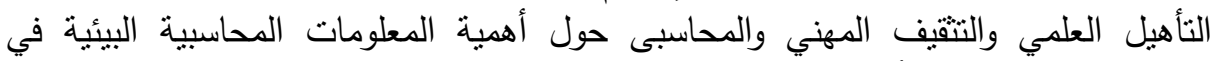
الأنشطة الصناعية كما أوصت الدراسة بضرورة توفير ونشر المعطيات الإحصائية المستفيضة المئة المئية

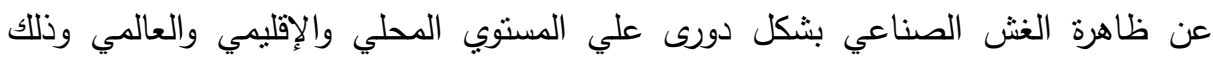
يساعد فى عمل التدقيق المحاسبي البيئي .

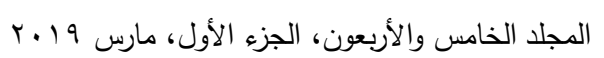




\section{ramadl}

لقد كان لعلم المحاسبة بإعنباره علما متعدد الفروع دورة البالغ الأهمية فى تتاول القضايا

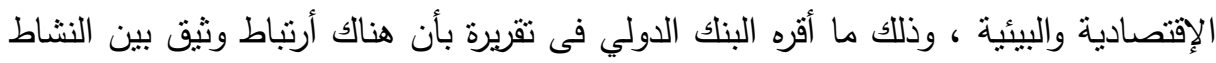

الإقتصادى والبيئة (Report national bank 1991, pp.5-6)

ونحن بحاجة إلي مؤشرات وأساليب تخلق نوعا من التكامل بين الإقتصاد والبيئة ، وأحد هذه الأساليب هي علم المحاسبه كمصدر هام من المصادر الأساسية التي تمد صانع القرار

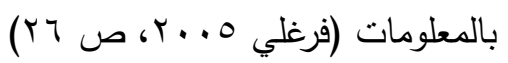
والمحاسبة البيئية من اهم الأمور التي تهنم بها هي الأهتمام بالقياس والتقييم المحاسبي

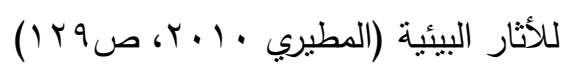

والنظره الحديثة للنظام الحاسبي تؤكد أنه نظام متكامل ومنماسك ينولي النظام خدمه

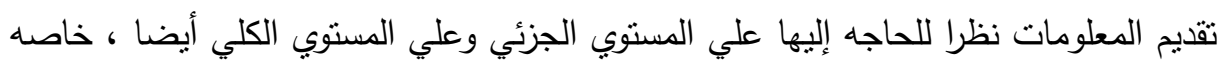

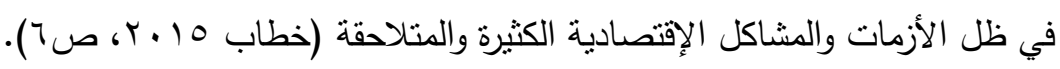
وبعد التحولات الكبري للعولمه وتحرير الأسواق وتطور وسائل الأتصالات والتقدم

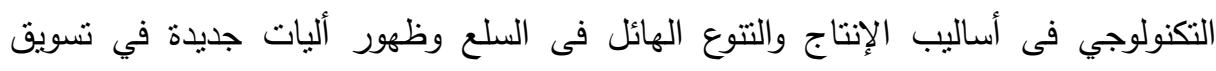
المنتجات ظهرت صور جديدة للغش الصناعي في تحدي جديد للإقتصاد والبيئة والتتمية وللفكر المحاسبي (Michele 2003.p1) والغش الصناعي تنتوع وتتتعب مخاطره البيئية

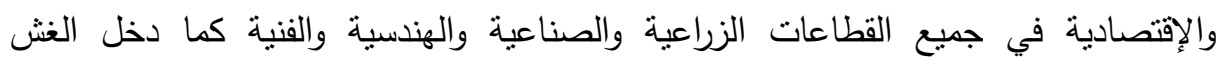
الصناعي فى أغلب السلع الإستهلاكية والغذائية وطال السلع الطبية والبيطرية (أرناؤوط

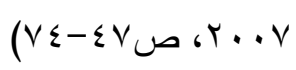

وإن لممارسات محاسبه التكاليف والمحاسبه الإداريه نأثير إيجابي نحو التصنيع المرشد

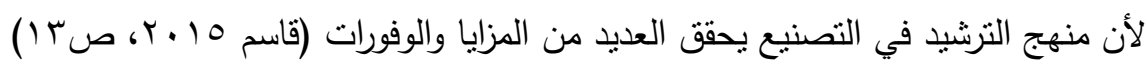

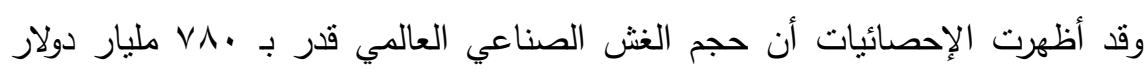

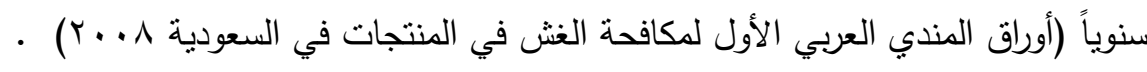

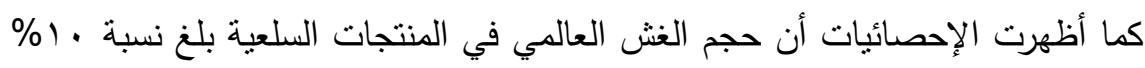

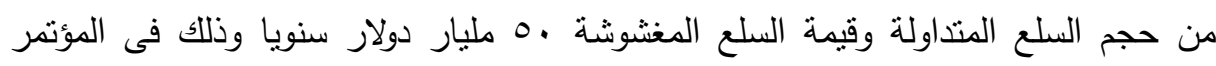

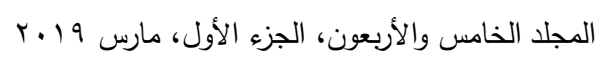


الإقليمي السادس حول تطبيق الملكية الفكرية عام با • ب ونظرا لأن المحاسبة الرقابية تتصب أدواتها علي السبب وليس النتيجة (الأثر) وأن القدره علي التحكم تكون متعلقه بالسبب وليس وليس

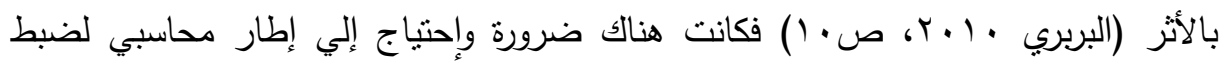

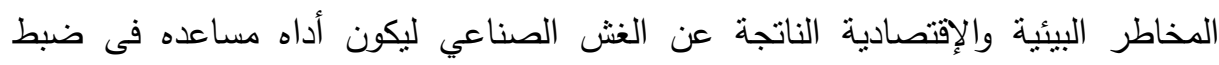
ومواجهه والحد من ظاهره الغش الصناعي.

\section{and}

أظهرت الإحصائيات مدي مخاطر الغش الصناعي ومدي تتوع المجالات التي يدخل فيها الغش الصناعي في كل من مصر والسعودية. أولاً: بعض المخاطر البيئية والإقتصادية للفش الصناعي في مصر: في تقرير منظمه الأغذيه والزراعه أن في مصر سوق عشوائي كبير لتصنيع المبيدات وتداولها (OECD organization Forecomomic co - operation and development ,

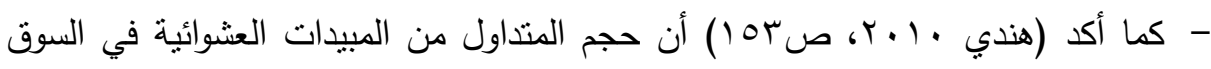
المصري يقدر •و\% وأن المبيدات المحظورة تسبب أمراضا مختلفة مثل الفشل الكلوي

$$
\text { والكبدي والسرطانات }
$$

- يصاب في مصر . .0 ألف شخص بالتسمم سنويا منهم .0 ألف يحتاجون لرعايه صحيه

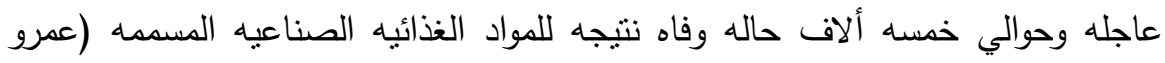

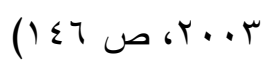

- قدرت مصانع بئر السلم وهي المسئول الأكبر عن الغش الصناعي فى مصر بحوالي ا, ــ مليون منشأة وأن حجم صناعات بئر السلم يقدر • مليار جنيه من حجم التجاره الداخليه

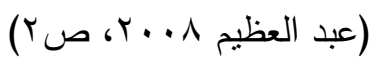

- تخطت شكاوي المواطنين من سلع الغش الصناعي خمسة ألاف شكوي عام r با ـ (جهاز حمايه المستهلك المصري) 
ثانياً: بعض المخاطر البيئية والإقتصادية للغش الصناعي في السعودية:

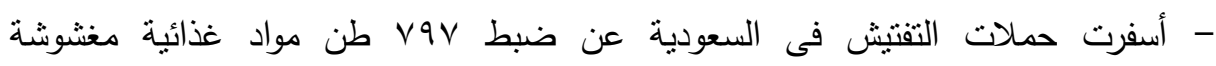

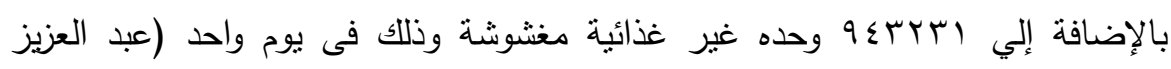

$$
\text { ( }
$$

- في عام 9 . . ت تم ضبط V مليون وحده مغشوشه في منافذ السعوديه (الجمارك السعودية (r...

- بلغت قيمه مضبوطات سلع الغش الصناعي عام 11 1 ـ ب بواسطه الجمارك السعوديه حوالي

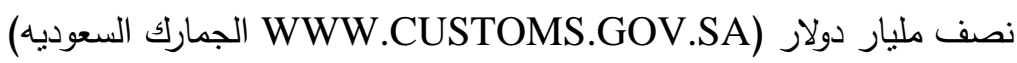
- قدرت خسائر الدوله السعوديه من الغش الصناعي حوالي 17 مليار دولا سنويا (الننتيا

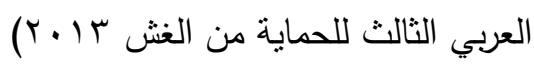

من العرض السابق لبعض صور الدخاطر البيئية والاقتصادية النانجة عن الغش

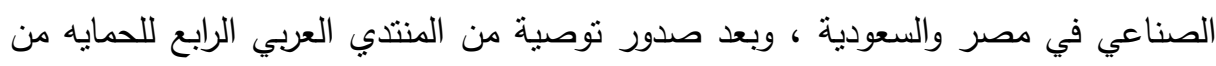

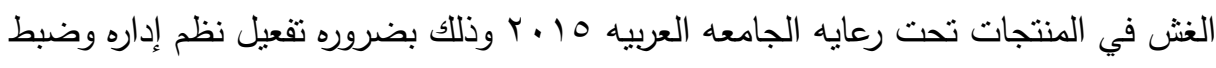

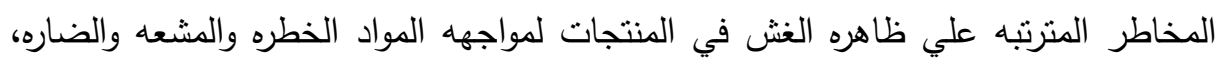

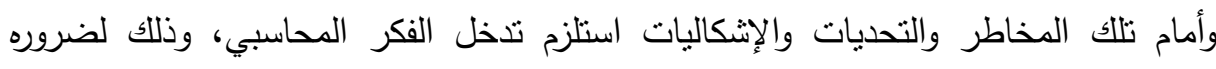

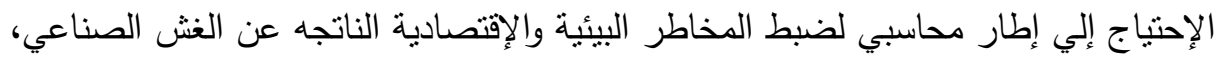

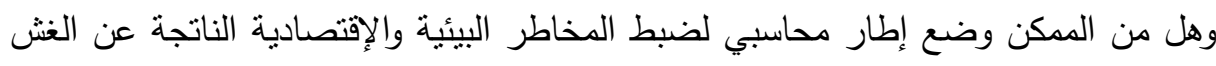

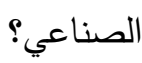

\section{تمساولاهت المهيد}

يمكن تلخيص مشكلة البحث من خلال التساؤلات الأتية:

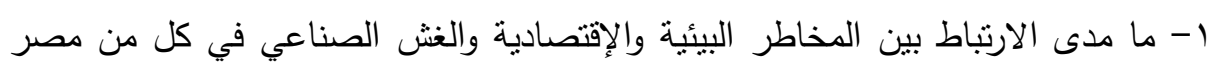
والسعودية؟ r- ما مدي العلاقة بين ضبط المخاطر البيئية والإقتصادية والغش الصناعي في كل من

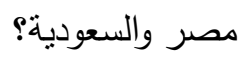


r- ما مدي الارتباط بين ضبط المخاطر البيئية والإقتصادية والمخاطر البيئية والإقتصادية

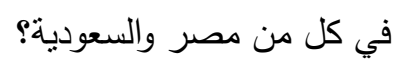

ع - ما إمكانية وضع إطار محاسبي مقترح لضبط المخاطر البيئية والإقتصادية الناتجة عن الغش الصناعي؟

\section{أهما اهخ المهيه}

1- دراسة وتحليل ظاهره الغش الصناعي مع توضيح المخاطر البيئيه والإقتصاديه المترتبه عليه من خلال نظام المعلومات المحاسبية فى كل من مصر والسعودية. r- دراسه دورالمحاسبه البيئية في التصدي للمشكلات الإقتصاديه والبيئيه الناتجه عن العمليه الصناعيه مع التركيز علي دور محاسبه التكاليف البيئية والمحاسبه الإداريه البيئيه فى لئه مواجهه مخاطر الغش الصناعي. r- التحقق من علاقه الغش الصناعي بالمخاطر البيئية والإقتصادية الناتجه عنه وبأطر ضبط مخاطره في كل من مصر والسعوديه. ع- وضع إطار محاسبي مقترح لضبط المخاطر البيئية والإقتصادية الناتجه عن الغش من فيط الصناعي. 


\section{هزوضر المهبه}

1- توجد علاقه معنويه طرديه بين المخاطر البيئية والإقتصادية والغش الصناعي في مصر . r- توجد علاقه معنويه بين ظبط المخاطر البيئيه والإقتصاديه والغش الصناعي في مصر .

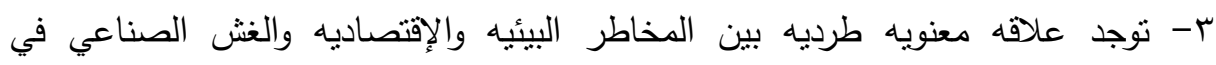
السعودية.

ع- توجد علاقه معنويه بين ضبط المخاطر البيئيه والإقتصاديه والغش الصناعي في السعودية.

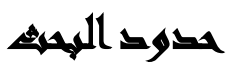

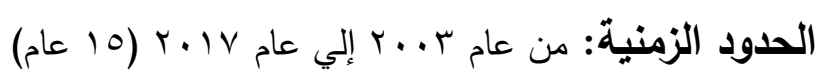

الحدود المكانية: جمهوريه مصر العربيه والمملكه العربيه السعوديه ( الثركات التي تتتج

السلع الاستهلاكية في مصر والسعودية)

الحدود البشرية: المجتمع المصري والمجتمع السعودي في ولي

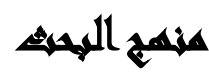

1- المنهج الإستنباطي: وذلك بالتعمق في دراسه المصادر الخاصه بموضوع الدراسه للوصول إلي أدق معلومات وبيانات في مصر والسعوديه.

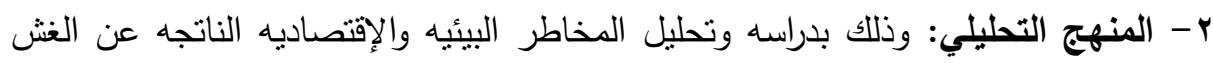
الصناعي في مصر والسعوديه.

r- المنهج الإستقرائي: وذلك بالإطلاع علي مجموعه من المراجع العلميه والنشرات والدراسات والأبحاث والتقارير من مصادرها الأصليه وذللك لتدعيم الإطار المحاسبي

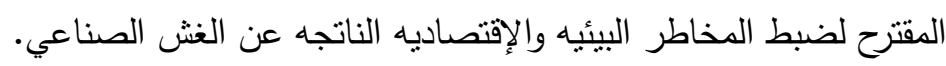
ـ - المنهج التاريخي: وذلك في عرض الدراسات السابقه في مصر والسعوديه والعالم للتعرف علي أراء وجهات نظر الباحثين السابقين في مجال الدراسه. 


\section{أهميه الهمهي}

يستمد هذا البحث أهميته لأن الدراسات السابقة لم تتطرق إلي وضع إطار محاسبي

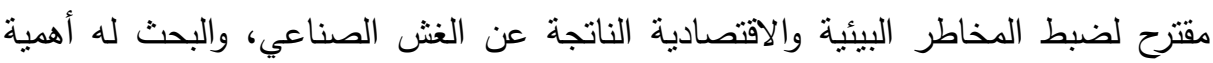

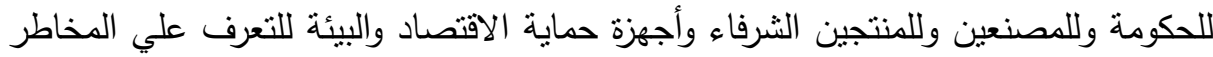

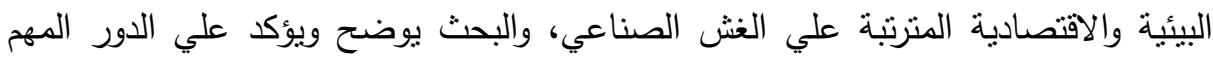
للفكر المحاسبي في ضبط المخاطر البيئية والاقتصادية الناتجة عن الغش الصناعي.

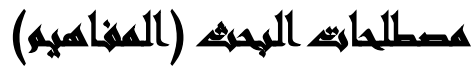

1- المحاسبة البيئية: هي النطاق الكلي للحاسبة من أجل حماية البيئة والتتمية المستدامة ( Association of chartered certified Accountants , 2004 , pp.

r - الغش الصناعي: هي ظاهره إقتصاديه سلبيه وخطيره يقوم بها مصنع غير مستوفي الإشتراطات الإقتصاديه والبيئيه لضوابط التشغيل ومعايير الإنتاج وكذلك بالإخلال في طرق الإنتاج السليمه والأمنه للمنتجات في أي مرحله من مراحل الإنتاج لمنتج وللظاهره

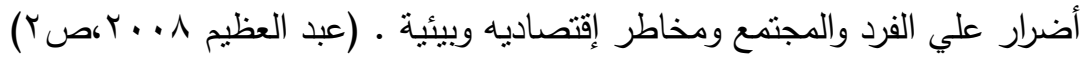
r- المخاطر البيئية والإقتصادية: هي أضرار متعدده ومنتعبه في مجالات وقطاعات عديده ناتجه عن الغش الصناعي وتأتي الثكاوي من المواطنين كرد فعل لوقوع ضرر

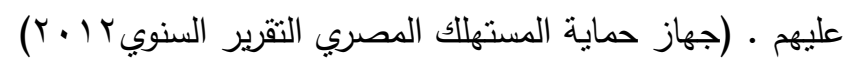
צ - ضبط المخاطر البييئه والإقتصادية: هي إجراءات لمحاوله المواجهه والحد من المخاطر الناتجه عن الغش الصناعي وتأتي المحاضر كإجراء من الأجهزه الرقابيه لمواجهه الغش الصناعي • (مصلحة الرقابة الصناعية المصرية - وثثقة سياسة الجودة

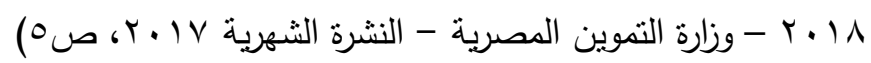




\section{السوراساهي الماريخد}

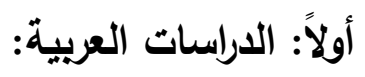

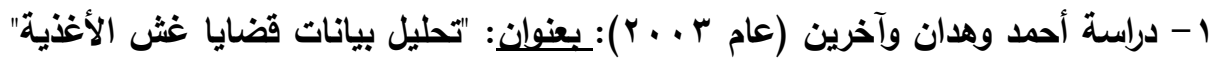

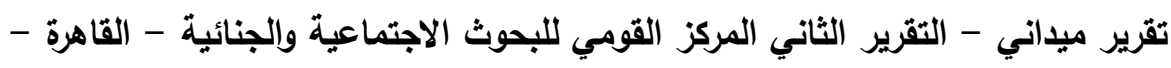

$$
\text { مصر. }
$$

أهمبة الدراسة: تحليل المضمون الكمي لعدد "مائة" ملف قضية من قضايا غش الأغذية.

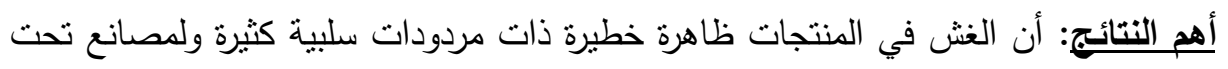
السلم دور كبير في ذلك.

أهم التوصبيات: يجب التوعية بالمخاطر الفردية والمجتمعية المترتبة على مختلف أساليب وصور الغش الغذائي.

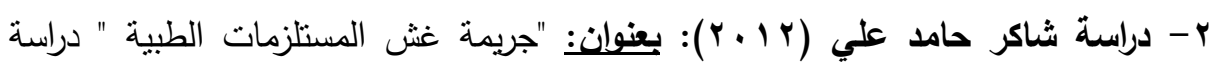

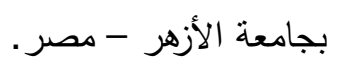

أهمية اللدراسة: أن غش المستلزمات الطبية يمس حياة الإنسان على وجه .

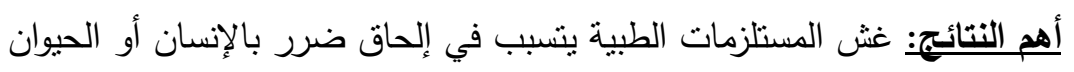

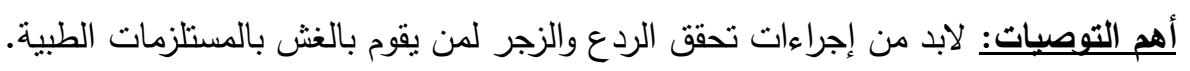

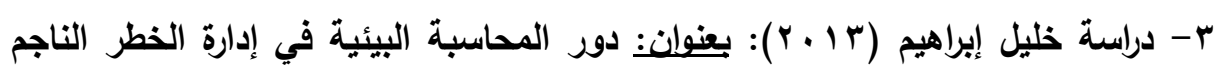
عن التلوث البيئيدراسة كلية الاقتصاد - جامعة الزيتونة - الأردن.

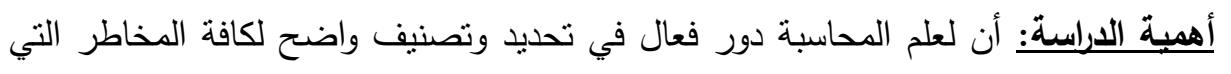

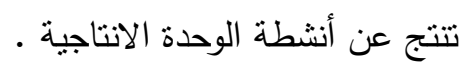

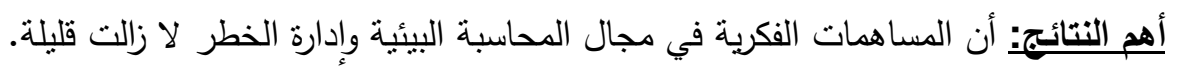

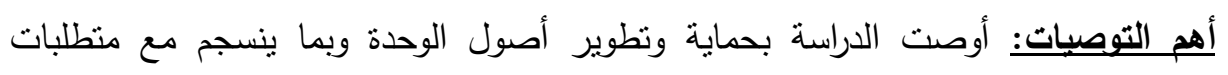

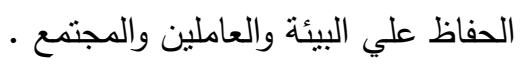




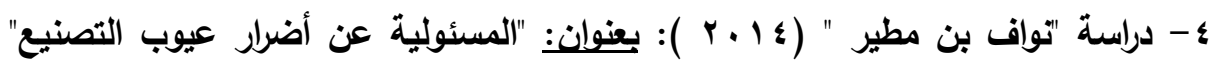

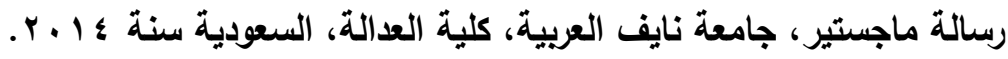

$$
\text { أهم أهبة الدراسية: معرفة المسئولية عن أضرار عبوب التصنيع. }
$$

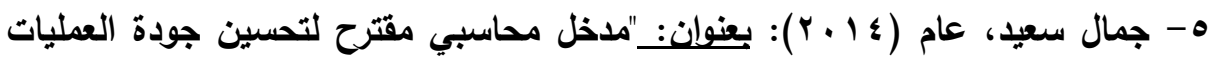

وخفض التكلقة باستخدام أساليب المحاسبة الإدارية الحديثة".

أهمبة الدراسة: توضيح أهمية دور المحاسبة البيئية في مواجهة الخطر الناجم من التلوثل البيئي.

أهم النتائج: أن الأساليب التقليدية للمحاسبة الإدارية أصبحت غير ملائمة في ظل التطورات الحديثة للشركات الصناعية.

أهم التوصبيات: لابد من الاستعانة بأساليب المحاسبة الإدارية الحديثة لمواكبة هذه النطورات العصرية المتلاحقة. ثانيا : الاراسات الأجنبيه צ- دراسة (Michele Forziey 2003) اتجلترا : أهمية الاراسة: بيان مخاطر الأدوية المغشوشة على الصحة العامة والأمان.والمجتمع

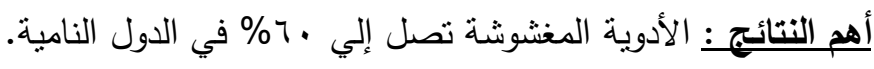
أهم التوصيات : لابد من القبام بإجرائات وقائية وحمائية من المنتجات الصيدلانية المغشوشة. (IBOPE 2005) ساوياولو - البرازيل:

أهمية الدراسة: أوضحت الدراسة قياس طلبات الناس للسلع المزيفة ومقدار شدة الششتروات لـات

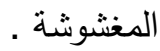

$$
\begin{aligned}
& \text { أهم النتائج: } 70 \text { \% من الذين استجابوا للحصر قاموا بشراء منتجات مغشوشة. } \\
& \text { أهم التوصيات: ضرورة تشجيع المنتجات الأصلية. }
\end{aligned}
$$

$$
\text { المجلد الخامس والأربعون، الجزء الأول، مارس 19 بـ }
$$


1- دراسة (Grossman and Saphiro 2006) في اندونيسيا: أهمية الدراسة: توضيح الأضرار الاقتصادية الكبيرة للغش التجاري في اندونيسيا أهم النتائج: نسبة الغش إلى المخرجات كبيرة في كل قطاع في اندونيسيا. أهم التوصبات: لابد من وضع إجرائات لمواجهة الاقتصاد الموازي. ج- دراسة (Zachary et. al 2008) الولايات المتحدة :

أهمية الدراسة: نوضيح التكاليف الخاصة بالتحكم البيئي خلال العمليات الانتاجية في الثركات.

أهم النتائج: أن التكاليف البيئية لمنشآت الأعمال أصبحت عاملاً مؤثراً في عملياتها.

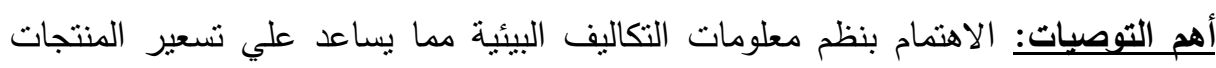
بشكل مناسب مع الحفاظ علي الجودة.

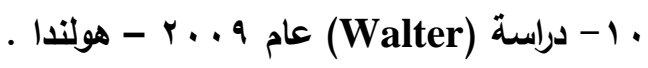

أهمبة الاراسة: أوضحت الدراسة مفهوم "تحسين الاستدامة" أي تقييم المنتج بشكل صحيح ومتوازن باستخدام المحاسبة البيئية والإدارة البيئية. أهم النتائج: أوجدت الدراسة أداة معيارية لتقييم دوره حياة شاملة لتحليل دوره حياة الإنتاج الصناعي. أهم التوصيات: أن يتم تقييم الأثر الاجتماعي باستخدام المؤشرات الاجتماعية المقترحة في الدراسة.

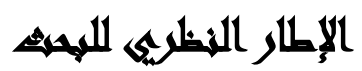

يتعرض البحث لوضع إطار محاسبي مقترح لضبط المخاطر البيئية والاقتصادية الناتجة عن الغش الصناعي ويعتبر قطاع الصناعة من أهم القطاعات المسئولة عن مسيرة التتمية،

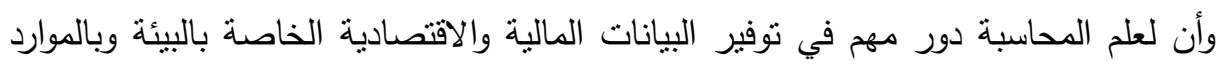

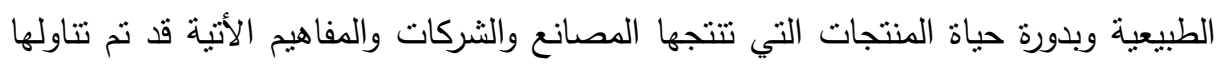
في البحث واستخدمت في الدراسة. 
تقييم الأداء البيئي: هو أسلوب بهدف إلي تحديد وقياس وتحليل وتتبع تكاليف ومنافع الأنشطة والبرامج البيئية التي تقوم بها المنشآت الصناعية لحماية البيئة من أضرار نشاطها الصناعي وذلك في ضوء مجموعة من الأهداف والمتطلبات والمعايير والمؤشرات والتقارير

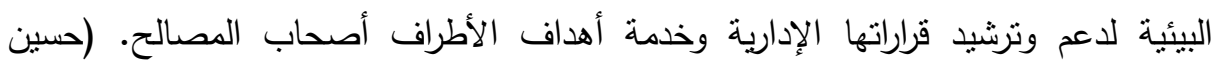

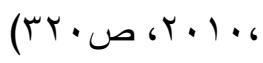
دورة حياة المنتج: هي عبارة عن مجموعة من المراحل المختلفة التي يمر بها المنتج منذ بداية التفكير في تصنيعه وحتى يتم التخلص منه، حيث يتم تقسيم مراحل هذه الدورة إلي ثناث

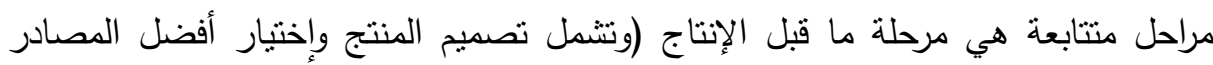

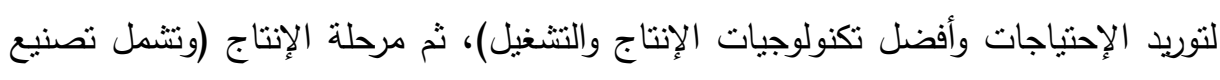
وتعبئة المنتج)، ثم مرحلة ما بعد الإتتاج (وتتثمل إستخدام المنتج ثم التخلص منده). المعايير البيئية: هي تلك المواصفات القياسية، المحلية أو الدولية التي ينم إعدادها

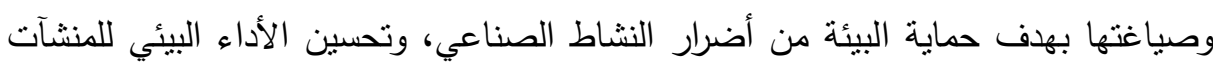

التكاليف البيئية: هي التضحيات التي تتحملها المنشأة في سبيل الإلتزام بأداء بيئي ينوافق مع التشريعات والمعايير البيئية، وبما يحافظ علي أصول وممتلكات المنشأة بالإضافة إلي تلبية رغبات المستهلكين والأطراف الخارجية، وذلك في صورة أنشطة وبرامج نضمن حماية البيئة من الأثار السلبية للتلوث وتضمن الإرتقاء بمتوى الأداء البيئي للمنشأة.

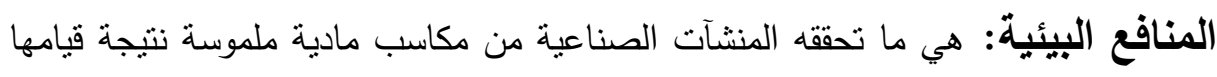
بالعديد من الأنشطة البيئية في الوقت الحالي لتجنب الإلتزامات البيئية المستقلية، وكذلك ما ماليه

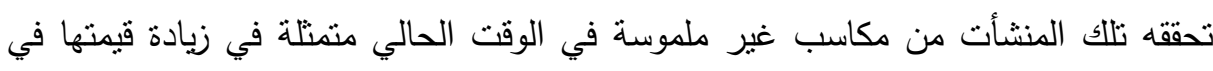
الأجل الطويل وتحقيق أرباح غير عادية نتيجة لإكتسابها شهرة بيئية بإعتبارها من المنشآت الصديقة للبيئة. 
مؤشرات الأداء البيئي: هي مقاييس (كمية ومالية) تستخدم لإدارة وقياس وتقييم الأداء البيئي للمنشآت الصناعية بهدف رفع كفاءة وفاعلية أنشطتها البيئية، وتسليط الضوه عليه كيفية تحسين أدائها البيئي والتعرف علي إمكانية خفض تكاليفها البيئية وتقديم معلومات

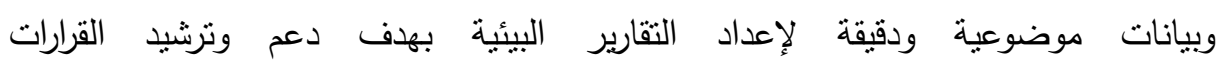

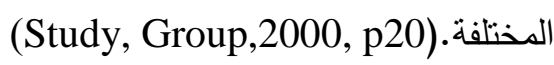
التقارير البيئية: هي وسيلة تنتخدم للإفصاح عن الأداء البيئي للمنشآت الصناعية، وقد

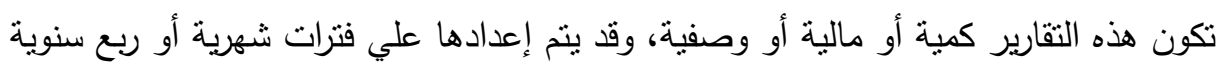

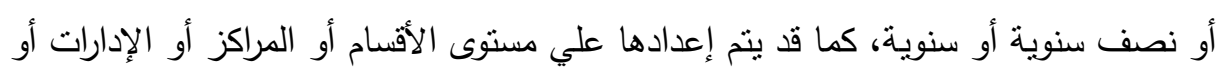

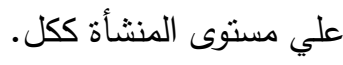

\section{إلجراعايه اللهمه}

\section{تكونت أدوات الاراسة في هذا البحث من:}

ا-المراجع، الدراسات السابقة، الكتب والمجلات والمقالات العلمية، والمؤتمرات، المنتديات،

r-النشرات والتقارير التي تقوم بها الجهات المختصة في مصر والسعودية - مصر - وزارة التموين والتجارة الداخلية - وزارة التضامن الاجنماعي - وزارة التجارة والصناعة - مصلحة الرقابة الصناعية - شرطة البيئة جهاز حماية المستهلك - هيئة

$$
\text { الرقابة الصناعية. }
$$

- السعودية - وزارة التجارة والصناعية - وزارة البيئة والزراعة - الجمارك السعودية - هيئة ومكافحة الغش والثقليد - حماية المستهلك السعودي. ץ-جمع البيانات والمعلومات من مصادرها من الجهات المختصة بخطابات معتمدة من معهد

$$
\text { الدراسات والبحوث البيئية . }
$$

ع-تم استخدام نظام المعلومات المحاسبية في جمع وفحص وتلخيص البيانات وتحويلها إلي معلومات.

ه-تم استخدام برنامج spss الإحصائي في إثبات أو نفي علاقات الارتباط وتحليل الانحدار. 
جدول(1): مقارنة بين مصر والسعودية توضح حصر وتلخيص أهم صور السلع الناتجة عن

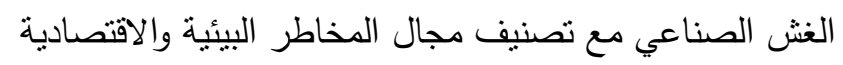

\begin{tabular}{|c|c|c|c|}
\hline مجال المخاطر & المعلكة العربية & مجال المخاطر & جمهورية مصر العربية(1) \\
\hline 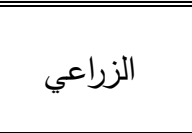 & مبيدات & 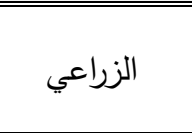 & سمكية أو - أعلاف داجنة - مبيدانية أو - \\
\hline الصحي & 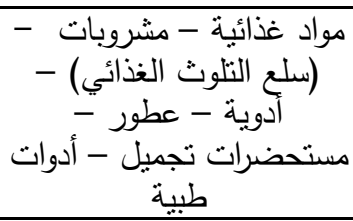 & 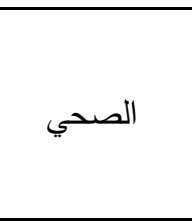 & 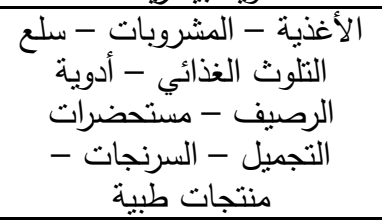 \\
\hline الصناعى & مستلزمات إنتاج & الصناعى & مستلزمات الإنتاج \\
\hline الهندسى & مواد البناء والمعدات & الهندسى & مواد البناء والمعدات \\
\hline الاجتماعي & 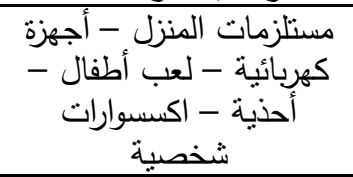 & الاجتماعي & الكهربائية والمنزلية والأدوات المنزية \\
\hline الكيزيائي - الإئي - & زيوت - أحبار - كيماويات - دهانات & & كيماويات - منظاريات - بويات صناعية \\
\hline 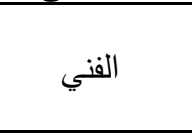 & الإطارات - الريداريون - مختلفة - مياه & الفني & قطع الغيار - أجهزة - إطارات \\
\hline الحضاري & ألعاب نارية (سلىع التلوث) & الحضاري & الألعاب النارية (سلع التلوثئ \\
\hline
\end{tabular}

المصدر: مصر وزارة التموين والتجارة الداخلية - وزارة التجارة والصناعة - جهاز حماية المستهلك مصلحة الرقابة الصناعية - من النقارير الثهرية والسنوية عن السنوات محل الدراسة.

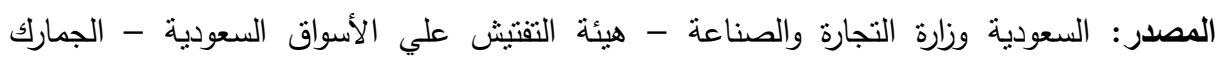

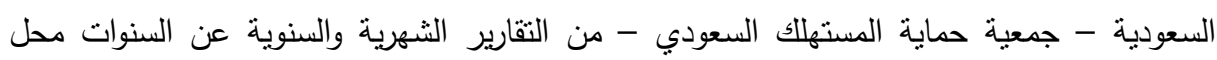


التعليق: بلاحظ تتوع وأختلاف وتعدد سلع الغش الصناعى كما انها تدخل فى اصناف سلع مختلفة

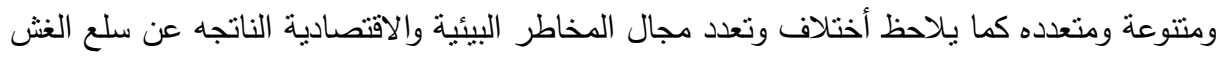
الصناعى خلال فترة الدراسة فى كل من جمهورية مصر العربية والمملكة العربية السعودية

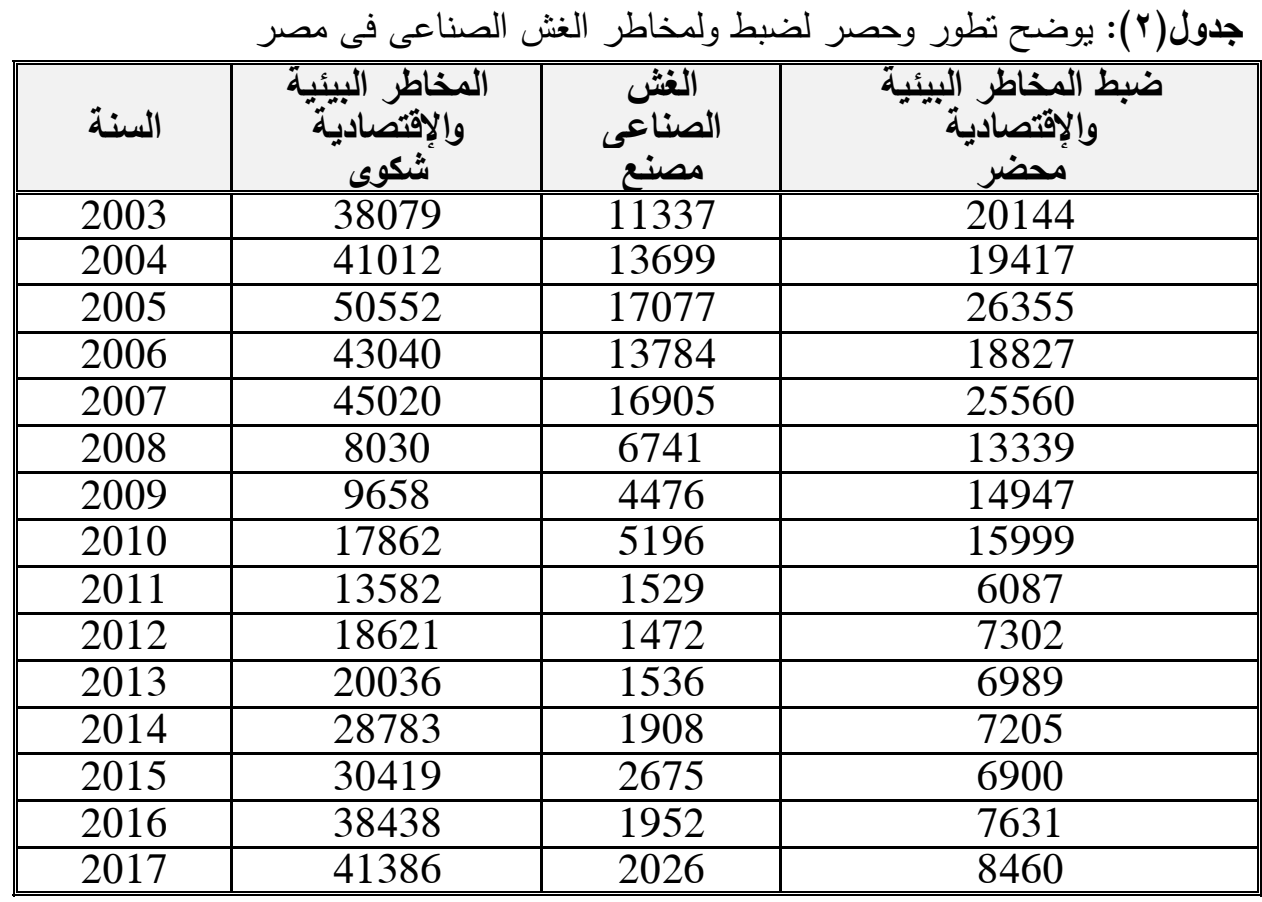

المصدر: وزارة التموين والتجارة الداخلية - مصلحة الرقابة الصناعية - جهاز حماية الدستهلك المصري، النشرات الثهرية، الثقارير السنوية - مصر .

التعليق: الجدول يوضح حصر فى مصر يوضح النطور وتتبع لضبط المخاطر البيئية

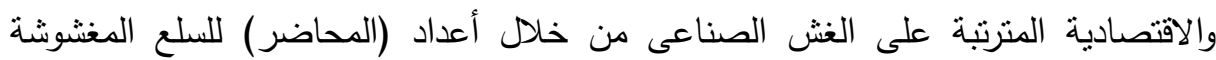
صناعيا والمحرره فى الاسواق وموضح بالجدول رد فعل المواطنين تعبيرا عن الأضرار البيئيه

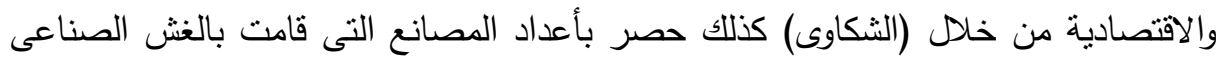

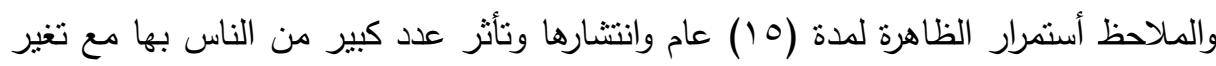
الظاهرة من عام إلى أخر . 
جدول(r): يوضح تطور وحصر لضبط ولمخاطر الغش الصناعى فى السعودية

\begin{tabular}{|c|c|c|c|}
\hline السنة & المخاطر البيائية والإقتّادية & | الغش الصناعح | مصنع & ضبط المخاطر البيئية والإقتصادية \\
\hline 2003 & 529 & 1794 & 156 \\
\hline 2004 & 2111 & 1951 & 115 \\
\hline 2005 & 838 & 656 & 109 \\
\hline 2006 & 3065 & 905 & 197 \\
\hline 2007 & 6618 & 1167 & 191 \\
\hline 2008 & 4334 & 1700 & 136 \\
\hline 2009 & 2734 & 2258 & 712 \\
\hline 2010 & 1792 & 1503 & 787 \\
\hline 2011 & 3385 & 1037 & 687 \\
\hline 2012 & 1888 & 1795 & 887 \\
\hline 2013 & 4099 & 1704 & 615 \\
\hline 2014 & 2914 & 1321 & 606 \\
\hline 2015 & 3023 & 899 & 562 \\
\hline 2016 & 3385 & 450 & 781 \\
\hline 2017 & 1695 & 123 & 249 \\
\hline
\end{tabular}

المصدر: وزارة التجارة والصناعة - هيئة التفتش علي الأسواق السعودية - الجمارك السعودية جمعية المستهلك السعودي - تقارير الجهود السنوية - السعودية.

التعليق: الجدول يوضح حصر فى السعودية لنطور وتتبع لضبط المخاطر البيئية والاقتصادية المترتبة على الغش الصناعى من خلال اعداد ( المحاضر) اللسلع المغشوشة صنائة صناعيا والمحرره فى الاسواق فى الاسواق وموضح بالجدول رد فعل المواطنين تعبيرا عن الأضرار

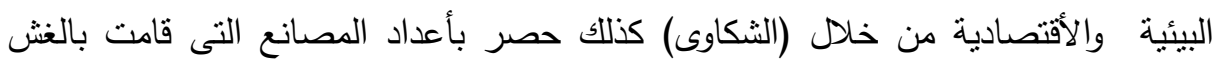

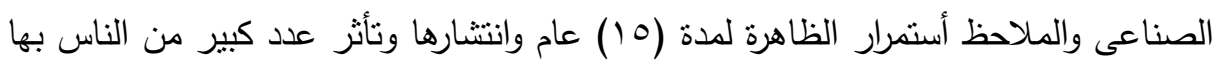

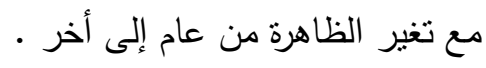


جدول(\&): معامل ارتباط سبيرمان لتوضيح العلاقة بين المخاطر البيئية والاقتصادية والغش

$$
\text { الصناعي في جمهورية مصر العربية. }
$$

\begin{tabular}{|c|c|c|}
\hline \multicolumn{2}{|c|}{ الغش الصناعي } & \\
\hline 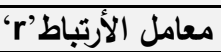 & قيمة الإحتمالية & \\
\hline 0.564 & $0.028 *$ & المخاطر البيئية والاقتصادية \\
\hline
\end{tabular}

الجدول السابق يوضح وجود علاقة معنوية طردية ذات دلالة إحصائية بين المخاطر

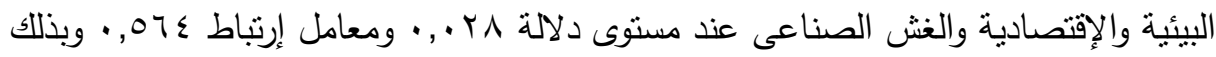
يمكن قبول فرضية وجود علاقة معنوية طردية بين المخاطر البيئية والإقتصادية والغش

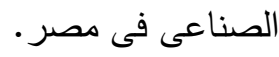

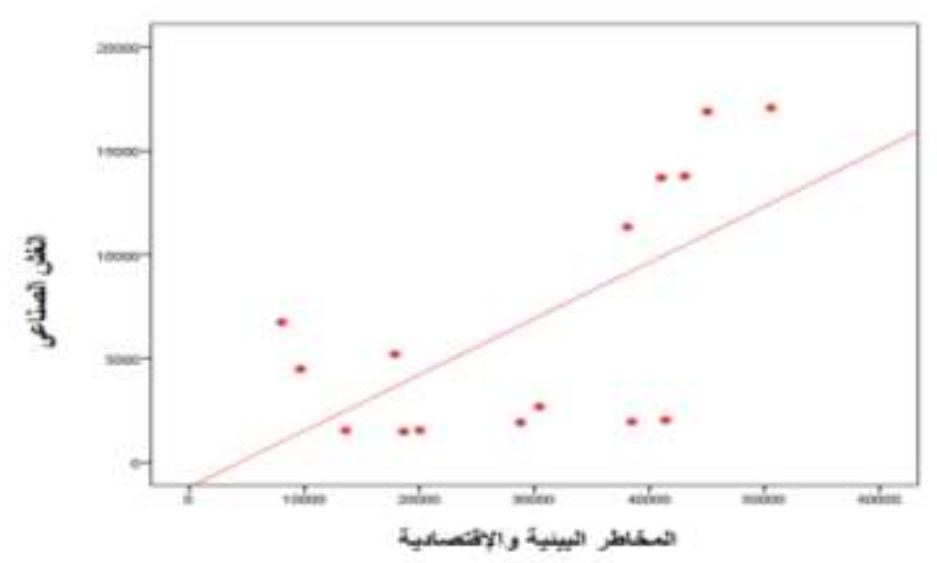

شكل(1): يوضح وجود علاقة طردية بين المخاطر البيئية والإقتصادية والغش الصناعى فى جمهورية مصر العربية جدول(ه): نموذج إنحدار خطى لبيان العلاقة بين المخاطر البيئية والإقتصادية والغش الصناعى لـ

\begin{tabular}{|c|c|c|c|}
\hline $\mathbf{R}$ & $\mathbf{R}$ Square & Adjusted R Square & $\begin{array}{c}\text { Std. Error of the } \\
\text { Estimate }\end{array}$ \\
\hline 0.632 & 0.399 & 0.353 & 4824.606 \\
\hline
\end{tabular}


مجلة العلوم البيئية

معهد الدراسات والبحوث البيئية - جامعة عين شمس

جدول رقم(7): تحليل التباين للعلاقة بين المتغيرين

\begin{tabular}{|c|c|c|c|c|c|}
\hline & Sum of Squares & df & $\begin{array}{l}\text { Mean } \\
\text { Square }\end{array}$ & $\begin{array}{c}\text { One } \\
\text { Way } \\
\text { ANOVA } \\
(\mathbf{F})\end{array}$ & P-value \\
\hline Regression & 201178818.272 & 1 & 201178818.272 & \multirow{3}{*}{8.643} & \multirow{3}{*}{$0.011^{*}$} \\
\hline Residual & 302598693.461 & 13 & 23276822.574 & & \\
\hline Total & 503777511.733 & 14 & & & \\
\hline
\end{tabular}

الغش الصناعى:Dependent Variable

Predictors: (Constant),المخاطر البيئية والإقتصادية

\begin{tabular}{|c|c|c|c|c|c|}
\hline & \multicolumn{2}{|c|}{$\begin{array}{l}\text { Unstandardized } \\
\text { Coefficients }\end{array}$} & \multirow{2}{*}{$\begin{array}{c}\begin{array}{c}\text { Standardized } \\
\text { Coefficients }\end{array} \\
\text { Beta } \\
\end{array}$} & \multirow{2}{*}{$\begin{array}{l}\text { t-test } \\
(\mathrm{t})\end{array}$} & \multirow{2}{*}{ Sig. } \\
\hline & B & Std. Error & & & \\
\hline (Constant) & -1198.607 & 2998.803 & & -0.400 & 0.696 \\
\hline والإقتصاطر البيئية & 0.271 & 0.092 & 0.632 & 2.940 & $0.011^{*}$ \\
\hline
\end{tabular}

الغش الصناعى:A Dependent Variable

الجدول السابق يوضح وجود علاقة معنوية طردية ذات دلالة إحصائية بين المخاطر

البيئية والإقتصادية والغش الصناعى. وبذلك يمكن قبول فرضية وجود علاقة معنوية طردية

بين المخاطر البيئية والإقتصادية والغش الصناعى فى مصر .

معامل ارتباط سبيرمان لتوضيح العلاقة بين المخاطر البيئية والاقتصادية والغش لإن

الصناعى فى المملكة العربية السعودية

جدول(^): معامل ارتباط سبيرمان لتوضيح العلاقة بين المخاطر البيئية والاقتصادية والغش

الصناعي في المملكة العربية السعودية

\begin{tabular}{|c|c|c|}
\hline \multicolumn{2}{|c|}{ الغش الصناعى } & \\
\hline 'r' معامل الأرتباط & قيمة الإحتمالية & \\
\hline-0.068 & 0.810 & المخاطر البيئية والأقتصادية \\
\hline
\end{tabular}

المجلد الخامس والأربعون، الجزء الأول، مارس 19 بـ إب 
الجدول السابق يوضح عدم وجود علاقة معنوية ذات دلالة إحصائية بين المخاطر

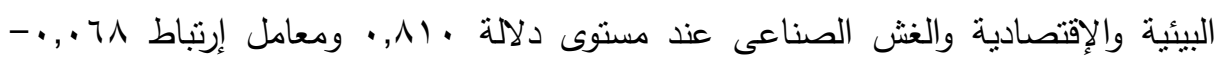

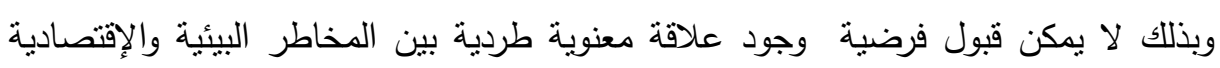

$$
\text { والغش الصناعى فى المملكة العربية السعودية. }
$$

جدول(9): معامل إرتباط سبيرمان لتوضيح العلاقة بين ضبط المخاطر البيئية والإقتصادية والغش الصناعى فى جمهورية مصر العربية

\begin{tabular}{|c|c|c|}
\hline \multicolumn{2}{|c|}{ الغش الصناعى } & \\
\hline 'r'r' معامل الأرتباط' & قيمة الإحتمالية & \\
\hline 0.896 & $<0.001 * *$ & ضبط المخاطر البيئية والإقتصادية \\
\hline
\end{tabular}

الجدول السابق يوضح وجود علاقة معنوية طردية ذات دلالة إحصائية بين ضبط الإية

المخاطر البيئية والإقتصادية والغش الصناعى عند مستوى دلالة ال |.,.•> ومعامل إرتباط 197, • • وبذلك يمكن قبول فرضية وجود علاقة معنوية طردية بين ضبط المخاطر البيئية

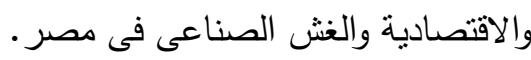

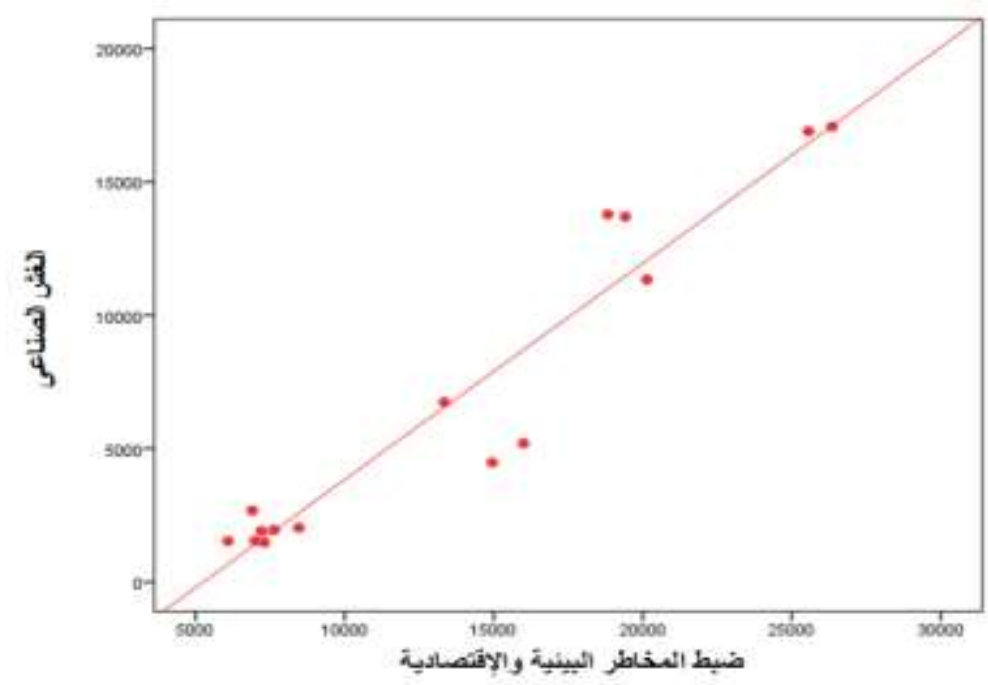

شكل رقم(ץ): يوضح وجود علاقة طردية بين ضبط المخاطر البيئية والإقتصادية والغش الصناعى فى جمهورية مصر العربية 
جلول رقم( • 1): نموذج إنحدار خطى لبيان العلاقة بين ضبط المخاطر البيئية والإقتصادية

\begin{tabular}{|c|c|c|c|}
\hline R & R Square & Adjusted R Square & $\begin{array}{c}\text { Std. Error of the } \\
\text { Estimate }\end{array}$ \\
\hline \hline 0.959 & 0.920 & 0.914 & 1759.006 \\
\hline
\end{tabular}

جدول رقم(1 1 ): تحليل التباين للعلاقة بين المتغيرين

\begin{tabular}{|c|c|c|c|c|c|}
\hline & $\begin{array}{c}\text { Sum of } \\
\text { Squares }\end{array}$ & df & Mean Square & $\begin{array}{c}\text { One Way } \\
\text { ANOVA } \\
\text { (F) }\end{array}$ & P-value \\
\hline Regression & 463554203.389 & 1 & 463554203.389 & \multirow{2}{*}{149.819} & $0.000^{* *}$ \\
\hline Residual & 40223308.344 & 13 & 3094100.642 & & \\
\hline Total & 503777511.733 & 14 & & & \\
\hline
\end{tabular}

الغش الصناعى:a. Dependent Variable

b. Predictors: (Constant),ضبط المخاطر البيئية والإقتصادية الصناعة جلول(r I): الدلالة الإحصائية بين ضبط المخاطر البيئية والاقتصادية والغش الصناعي في :D

\begin{tabular}{|c|c|c|c|c|c|}
\hline & \multicolumn{2}{|c|}{$\begin{array}{l}\text { Unstandardized } \\
\text { Coefficients }\end{array}$} & \multirow{2}{*}{\begin{tabular}{|c}
$\begin{array}{c}\text { Standardized } \\
\text { Coefficients }\end{array}$ \\
Beta
\end{tabular}} & \multirow{2}{*}{$\begin{array}{l}\text { t-test } \\
(\mathrm{t})\end{array}$} & \multirow{2}{*}{ Sig. } \\
\hline & B & $\begin{array}{c}\text { Std. } \\
\text { Error }\end{array}$ & & & \\
\hline (Constant) & -4270.586 & 1013.608 & & -4.213 & $0.001^{* * *}$ \\
\hline |لبيئة والإقتصادرية & 0.811 & 0.066 & 0.959 & 12.240 & $0.000 * *$ \\
\hline
\end{tabular}

الغش الصناعى:a. Dependent Variable

الجدول السابق يوضح وجود علاقة معنوية طردية ذات دلالة إحصائية بين ضبط

المخاطر البيئية والإقتصادية والغش الصناعى. وبذلك يمكن قبول فرضية وجود علاقة معنوية

طردية بين ضبط المخاطر البيئية والإقتصادية والغش الصناعى فى مصر . 
جدول(T M): معامل إرتباط سبيرمان لتوضيح العلاقة بين ضبط المخاطر البيئية والإقتصادية والغش الصناعى فى المملكة العربية السعودية

\begin{tabular}{|c|c|c|}
\hline \multicolumn{2}{|c|}{ ضبط المخاطر البيئية والأقتصادية } & \\
\hline معامل الأرتباط'r' & قيمة الإحتمالية & \\
\hline 0.100 & 0.723 & الغش الصناعى \\
\hline
\end{tabular}

الجدول السابق يوضح عدم وجود علاقة معنوية ذات دلالة إحصائية بين ضبط

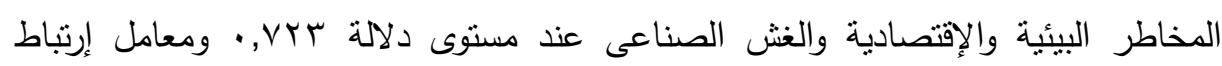
· . . . . وبذلك لا يمكن قبول فرضية وجود علاقة معنوية طردية بين ضبط المخاطر البيئية والإقتصادية والغش الصناعى فى المملكة العربية السعودية.

الإطار المحاسبى المقترح لظبط المخاطر البيئية والإقتصادية الناتجة عن الغش الصناعى:

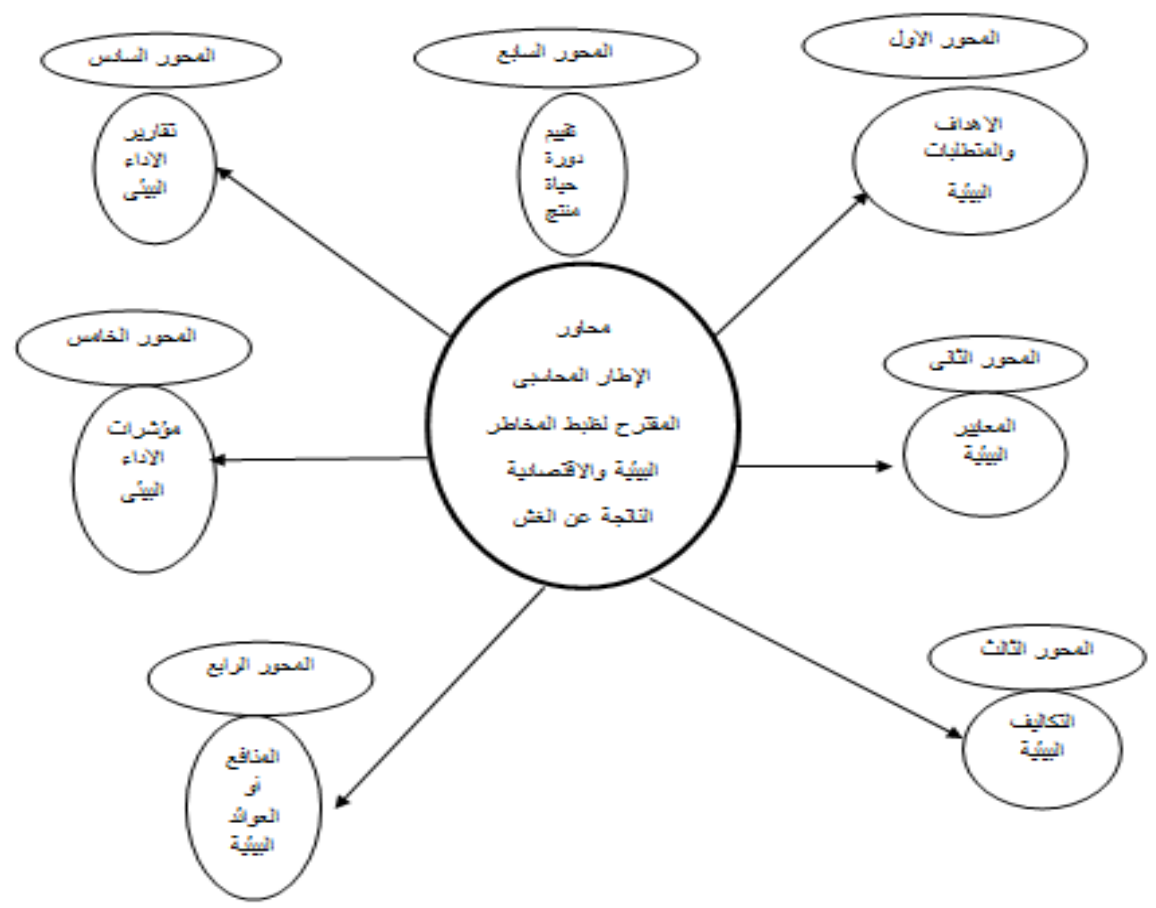




\section{الأهداف الاستراتيجية للاطار المحاسبى المقترح لظبط المخاطر البيئية

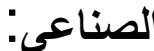 الغش عن الناتجة

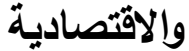

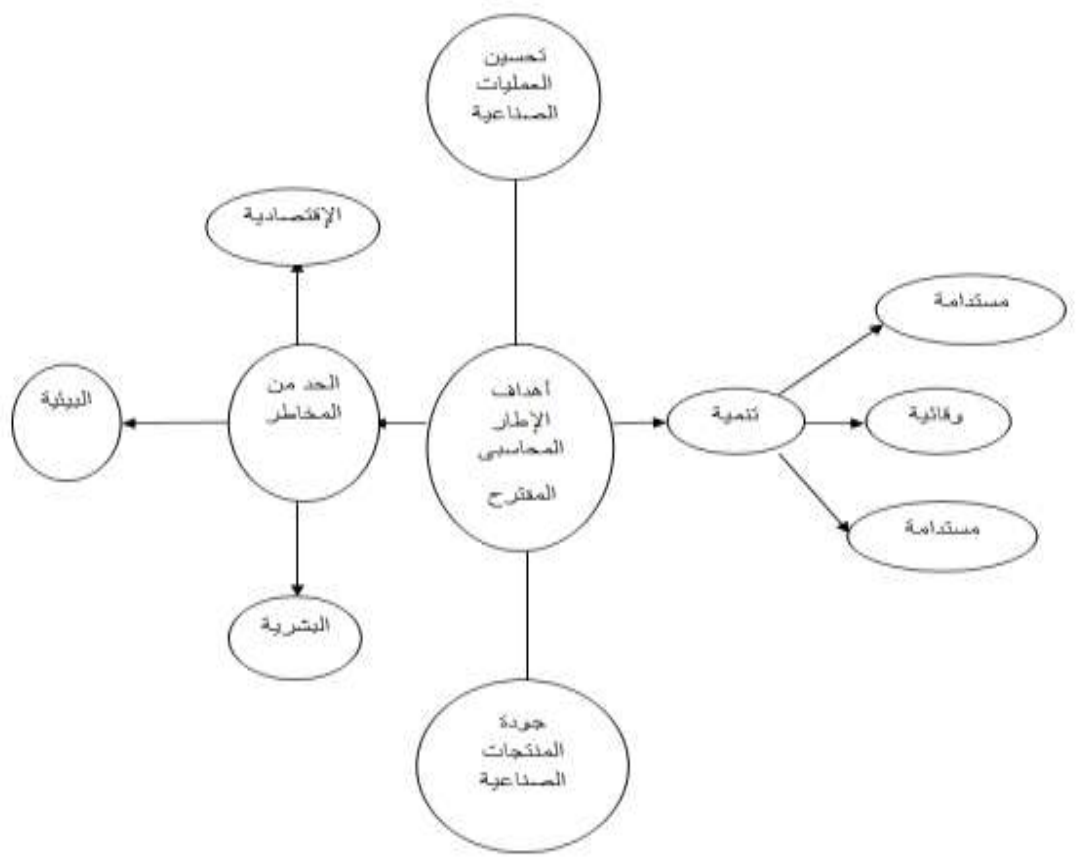

1-توصلت الدراسة إلى أنه نوجد علاقة معنوية طردية بين المخاطر البيئية والأقتصادية

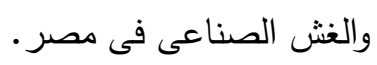

r-توصلت الدراسة إلى انه نوجد علاقة معنويه طرديه بين ضبط الدخاطر البيئية

$$
\text { والأقتصادية والغش الصناعى فى مصر . إلى }
$$

r-توصلت الدراسة إلى أنه لا نوجد علاقة معنوية ذات دلاله أحصائية بين المخاطر البيئية

$$
\text { والأقتصادية والغش الصناعى فى السعودية. }
$$

ع-توصلت الدراسة إلى أنه لا توجد علاقة معنوية ذات دلاله أحصائيه بين ضبط المخاطر

$$
\text { البيئية والأقتصادية والغش الصناعى لألى فرد السعودية. }
$$


ه-يمكن من خلال الفكر المحاسبي وضع إطار لضبط المخاطر البيئية والاقتصادية الناتجة عن الغش الصناعي.

\section{التحوبياهت}

1-يقترح الباحثون ضرورة الأهتمام بنطوير كفاءة منظمات حماية البيئة وتوفير التأهيل العلمى والتثقيف المهنى والمحاسبي حول أهمية المعلومات المحاسبية البيئية فى الأنشطة

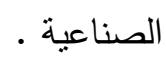

r-يقترح الباحثون ضرورة نوفير ونشر المعطيات الأحصائية المستفيضة عن ظاهرة الغش الصناعى بشكل دورى على المستوى المحلى والأقليمى والعالمى وذللك يساعد فى عملية

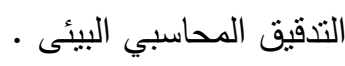
r-يقترح الباحثُن تحديث مؤشرات قياس وتقييم الأداء البيئى فى الثركات والمصانع بحيث

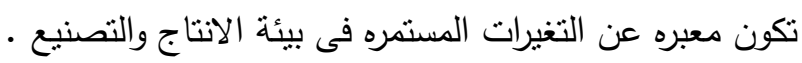

ع-يقترح الباحثون الاهتمام بنطبيق الاطار المحاسبي المقترح لأن ضبط المخاطر البيئية والاقتصاديه الناتجه عن الغش الصناعى سيسهم فى المحافظة على البيئة والموارد

$$
\text { الطبيعية والبشرية. }
$$

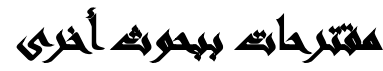

القيام ببحوث ودراسات فى كل مجال أو كل قطاع يدخل فيه الغش الصناعى ببحوث

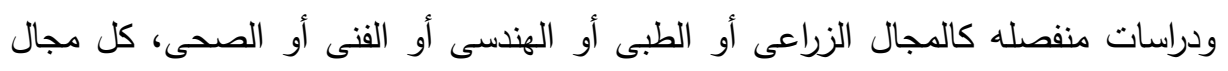
بدراسة متخصصة أو بحث مستقيض منفصل على حدات

\section{المرالئan}

أحمد المطيري (سنة • ( • ب): "منهج مقترح لمحاسبة المسئولية عن التكاليف البيئية " رسالة

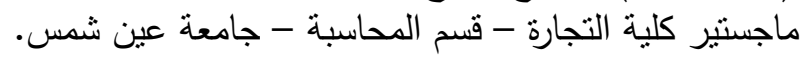

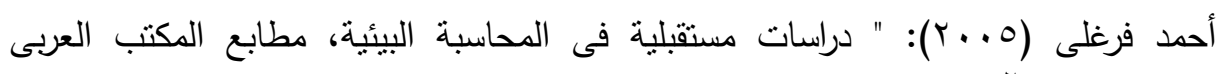


الجمارك السعودية " التقارير السنويه " السعوديه 9 . . ץ .

جمال سعد خطاب(0 (ب)): " دراسات فى المحاسبة الادارية، مكتبة عين شمس مصر " "

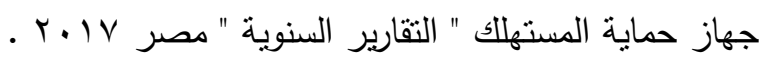

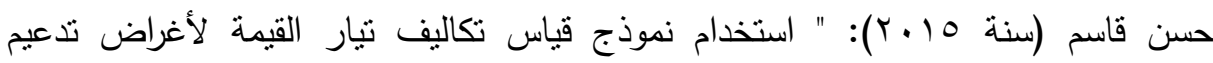
استراتيجية الاستدامة في ظل بيئة التصنيع المرشد " رسالة دكتوراه - كلية

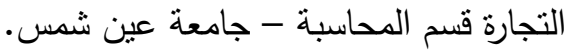

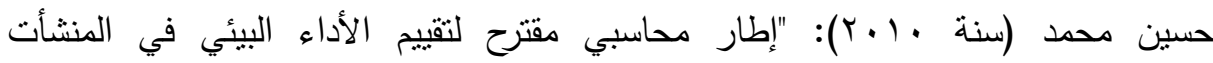

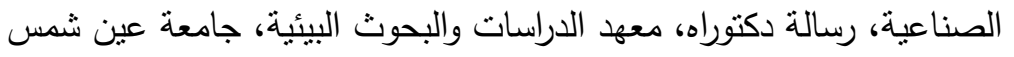

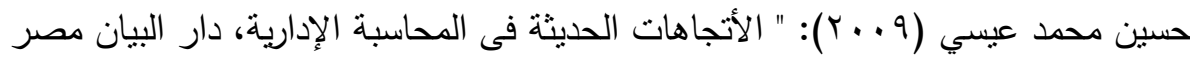

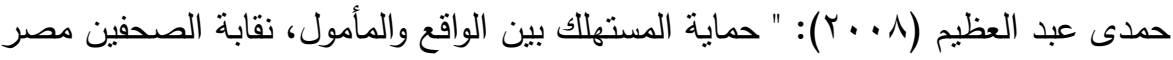

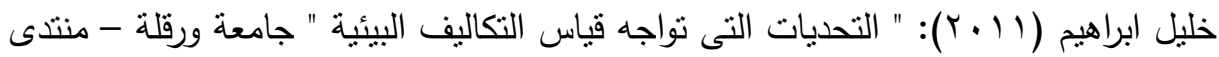
دولى

رفيق البربري " البعد الاستراتيجي للتكاليف التسويقية وأثنره في تحقيق الميزة التتافسبة في ظل متغيرات بيئه الأعمال الحديثة" رسالة ماجستير - كلية التجارة - قسم المحاسبة

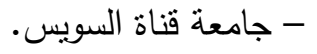

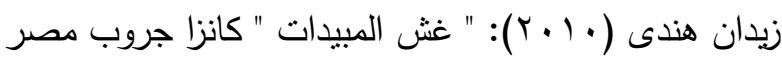

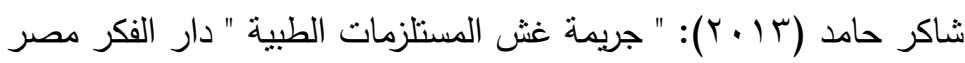
طارق حماد(r ..r): " دور معلومات المحاسبة الادارية فى بناء الأستراتيجية المتوازنة لللمنظمة " كلية التجارة - عين شمس.

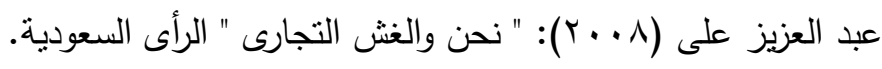

عبداله حسين (ץ . . ץ): " حماية المستهلك من الغش التجارى والصناعى " دار النهضة مصر

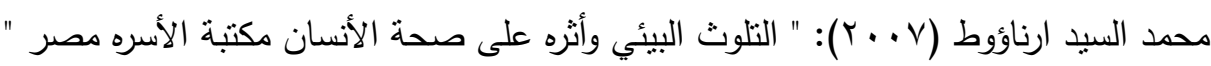

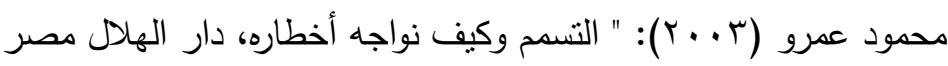

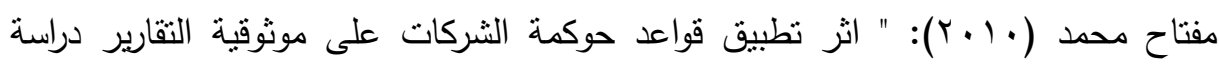
تطبيقيه 


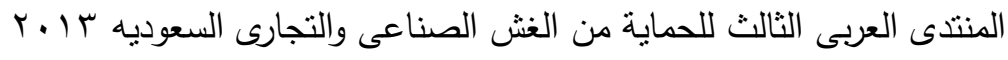

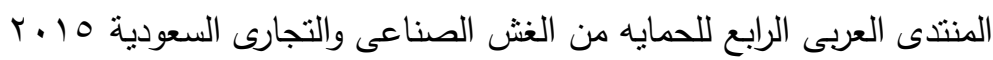

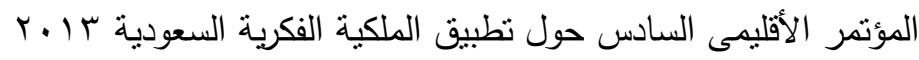

$$
\begin{aligned}
& \text { نادر نور الدين " الأهرام، العدد }
\end{aligned}
$$

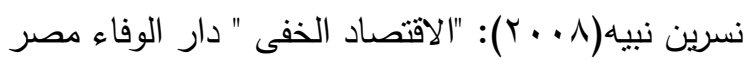

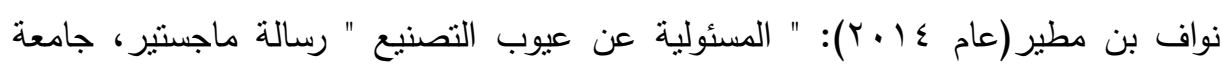

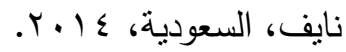

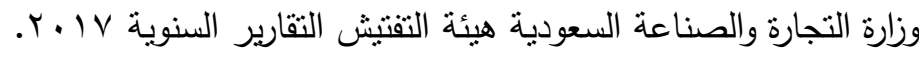

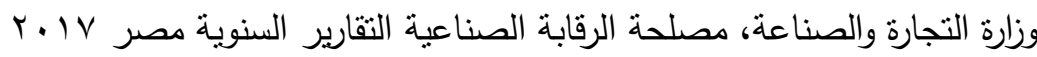

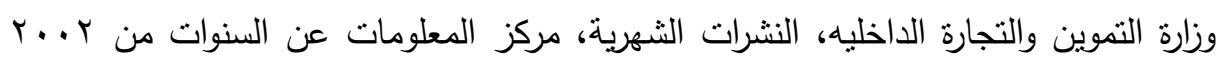

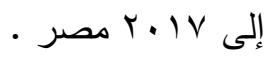

Anna influence of the Economic Cycle on the product life cycle of a territory " Publication Type : Journal Article, Issue, 2012.

Carla " Modeling the Economic and Environmental Performance of Engineering Products : Public at Type : Journal 2012.

Forziey, JD, MPH, (2005): Authur of Counterfeit Good and the public's Health and safety,.

Galup : Marketing News. U.S.A.2005

Grossman ASEAN - intellectual Property Rights- co-operation Programme 2000

IBOPE, opiniao Publica, Sao Paulo- Brasil, 2000.

Innkamp, "the interest of consumer in Ecological product "Journal of consumer policy (Vol.2 .2000)

OECD organization for economic co-operation and development, 2007.

Report national Bank; 1991.

Study, Group, of Environmental system, Developing an Environmental system japan Agency, march 2000, p20.

$$
\text { المجلد الخامس والأربعون، الجزء الأول، مارس } 9 \text { ب. }
$$




$$
\text { معهد الدراسات والبحوث البيئية - جامعة عين شمس البيئة }
$$

Simo'es (2013): " integrating Environmental and Econon life cycle analysis in product Development. Publication type jollrnal.

Simon, op "How Your product to Be Environmental Friend? Journal of Business (Vol. 11. 1995)

Walter (2009): " Life cycle Based Susttain ability Assessme of products, Springer nether lands.

www.Customs.Gov.sa

A SUGGESTED ACCOUNTING FRAMEWORK TO

ADJUST ENVIRONMENTAL AND ECONOMIC

RISKS RESULTING FROM INDUSTRIAL FRAUD

A COMPARATIVE STUDY BETWEEN EGYPT AND

\title{
SAUDI ARABIA
}

Yasser, H. E Salem ${ }^{(1)}$; Tark, AHamad ${ }^{(2)}$ and Magda, A. Gerbril ${ }^{(3)}$ 1) Higher Institute of Cooperative and Managerial Studies 2) Faculty of Economics, 6th of October University 3) Faculty of Commerce, Ain Shams University

\begin{abstract}
The study aimed to address the phenomenon of industrial fraud in order to reduce the cost of environmental and economic risks resulting from industrial fraud in a comparative study between Egypt and Saudi Arabia. The study aimed to develop a proposed accounting framework to control the environmental and economic risks resulting from industrial fraud. And clarifying the environmental and economic risks resulting from industrial fraud in both Egypt and Saudi Arabia. The study reviewed the role of environmental accounting in solving the
\end{abstract}

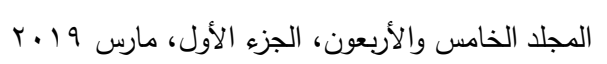


problems resulting from the industrial process. A proposed accounting framework to control environmental and economic risks resulting from industrial fraud. The results of the study showed that there is a significant positive correlation between industrial fraud and environmental and economic risks in Egypt. The results also indicate that there is no significant relationship between industrial fraud and environmental and economic risks in Saudi Arabia. Among the recommendations of the study is the need to pay attention to the development of all environmental protection organizations and to provide scientific qualification and professional and accounting education on the importance of environmental accounting information in industrial activities. The study also recommended the need to provide and disseminate statistical data on the phenomenon of industrial cheating periodically at the local, regional and global levels, Environment.

The importance of the study is because the previous studies did not address the development of a proposed accounting framework to control the environmental and economic risks resulting from industrial fraud and the accounting framework proposed for the study is of importance to the government and the honorable manufacturers and the protection of economy and the environment and to preserve natural and human resources. 